\title{
La literatura escrita por mujeres y los movimientos estudiantiles de los años 1960: Los relatos de Elena Poniatowska y Etsuko Takano
}

\author{
Cuadernos CANELA, 31, pp. 45-57 \\ Recibido: 01-X-2019 \\ Aceptado: 28-IV-2020 \\ Publicado, versión impresa: 22-V-2020 \\ ISSN 1344-9109 \\ Publicado, versión electrónica: 22-V-2020 \\ ISSN 2189-9568 \\ (C) La autora 2020 \\ canela.org.es
}

\author{
María Lucía Correa \\ Universidad de Kioto, Japón
}

\section{Resumen}

El objetivo de este artículo es comparar dos relatos escritos por mujeres en el contexto de los movimientos estudiantiles de la década de 1960: La noche de Tlatelolco de Elena Poniatowska, en México, y El origen de mis veinte años de Etsuko Takano, de Japón, ambos publicados en 1971. El texto de Poniatowksa presenta la multiplicidad de voces que constituyeron el movimiento estudiantil mexicano de los años sesenta, y a través de un montaje narrativo polifónico ofrece una alternativa para el diálogo que le fue negado a los estudiantes. El diario de Takano, por su parte, escrito en un tono íntimo, confesional y lleno de angustia, retrata al movimiento estudiantil como el fondo sobre el cual aparecen las preguntas por la propia identidad. Ambas autoras, aunque con formas literarias muy diferentes, comparten el hecho de relatar los turbulentos años de protesta desde perspectivas opuestas a la narrativa histórica u oficial: Poniatowska desde el diálogo abierto y Takano desde el monólogo íntimo.

\section{Palabras clave}

Elena Poniatowska, Etsuko Takano, movimientos estudiantiles, 1960

\section{Introducción}

Desde el nacimiento de la institución universitaria, los actos de resistencia y rebelión estudiantil han sido fundamentales para la historia y la estructura política de muchos países (Boren, 2001, p. 3). Pero los movimientos estudiantiles no solo han sido fenómenos en los que se entrecruzan lo político, lo educativo y lo social, sino que también han sido el terreno fértil del que han nacido diversas manifestaciones artísticas sobre la inconformidad y la contestación.

Sin embargo, no solo son pocas las veces que se miran los movimientos estudiantiles desde la literatura, sino que son muchas menos las que se los piensa desde una perspectiva femenina. Quizás por haber sido un movimiento mayoritariamente compuesto por hombres pareciera - erróneamente - que son inexistentes las narrativas femeninas sobre la rebelión estudiantil: prueba de este error son los textos a los que aquí nos dedicaremos.

En ese orden de ideas, el interés que anima este artículo es el de explorar lo que la literatura escrita por mujeres tiene por decir sobre esos movimientos, cómo los ha narrado, qué registro ha hecho de ellos. El objetivo del artículo es comparar, tanto como esto sea posible cuando se trata de narrativas muy disímiles, dos textos literarios escritos por mujeres en el contexto de los movimientos estudiantiles de la década de 1960. La 
lectura paralela de estos dos textos nos permitirá ver los puntos de encuentro y las diferencias entre los movimientos estudiantiles en México y Japón.

El primero de ellos es La noche de Tlatelolco de Elena Poniatowska, una crónica publicada en 1971 que recoge las voces de personas involucradas, directa o indirectamente, con la masacre ocurrida en la Plaza de las Tres Culturas en la Ciudad de México el 2 de octubre de 1968. El segundo texto es El origen de mis veinte años 『二十歳の原点』, de Etsuko Takano, también publicado en 1971, un diario íntimo y confesional de una estudiante de la Universidad Ritsumeikan, en Kioto, activista y partícipe del movimiento Zenkyoto, que murió arrojándose a las vías del tren el 24 de junio de 1969.

Al escoger para esta lectura comparada dos textos escritos por mujeres estamos dando una mirada feminizadora al movimiento estudiantil, algo que si bien no es impensable tampoco es necesariamente evidente: los movimientos sociales en general, a excepción por supuesto de los movimientos feministas, no suelen verse como asuntos de mujeres, o como asuntos de interés feminista. Sin embargo, es importante recordar que el nacimiento de los movimientos de liberación femenina, particularmente en lo que tiene que ver con la organización y politización del movimiento, se debe en buena parte al aliento que tomó de las organizaciones estudiantiles de los años sesenta (Thompson, 2002).

Antes de dar una mirada cuidadosa a cada obra y hacer una lectura comparada de las dos, haremos un breve recorrido por los conceptos básicos que delimitan el marco que las reúne: los movimientos sociales y los movimientos estudiantiles.

\section{Movimientos sociales}

¿De qué se habla cuando se habla de movimientos sociales? Los movimientos sociales pueden ser definidos como esfuerzos comunitarios organizados que buscan bien sea promover u oponerse a un cambio social, sea éste, por ejemplo, una medida que afecte a un sector de la población, o la necesidad de oponerse al statu quo de un gobierno, o incluso la búsqueda de una transformación social de mayor escala (Marx y McAdam, 1992, p. 3, citados en Thompson, 2002, p. 712).

Los movimientos sociales son formas colectivas de acción política, es decir que, por una parte, se nutren de la acción colectiva - movilización, protesta, etc. - para existir, y por otra están concernidos con la colectividad mayor y las decisiones de poder que recaen sobre ella (ver Melucci y Massolo, 1991). Además, los movimientos sociales cuentan con la característica particular de ser no institucionales; no son organizaciones en sí mismos, no están institucionalizados ni cuentan con el apoyo de éstas, sino que se rigen estrictamente por la interacción entre diferentes actores sociales (Chesters y Welsh, 2011, p. 13).

Si entendemos los movimientos sociales como la aparición en la esfera pública de formas colectivas no institucionalizadas, sus orígenes podrían ser rastreados a momentos tan lejanos como el surgimiento del ágora o la aparición de la dicotomía y rivalidad entre grupos dominantes y grupos sometidos. Sin embargo, hay una particularidad exclusiva de los movimientos sociales que los hace diferentes de otras formas de resistencia organizada, por ejemplo, los movimientos independentistas en Latinoamérica, o la revolución francesa. La diferencia entre los movimientos sociales y otras formas de protesta social radica en el hecho de que los movimientos sociales surgen particularmente dentro del modelo económico moderno de producción (capitalista) y dentro de las tensiones que este modelo acarrea (Chesters y Welsh, 2010, pp. 34-35). 
Así, los movimientos sociales por definición encarnan una lucha por la representación o inclusión de comunidades marginales dentro de un modelo de producción industrializado, que es necesariamente segregacionista. Los movimientos obrero y socialista son ejemplo de esto: la demanda de los grupos oprimidos dentro del modelo industrializado es llevada a las esferas de poder a través de mecanismos de protesta que tienen un impacto directo en la producción, como la huelga, etc., y un requerimiento específico de participación dentro del sistema es puesto en evidencia. En general, estas demandas son específicas, igualitarias, materialistas y concretas: ingreso equitativo, derecho de participación política (derecho al voto), autonomía política de las clases trabajadoras, etc.

\section{Nuevos movimientos sociales}

Estos viejos movimientos sociales se originan, pues, en la dinámica económica y política del siglo XIX, en la lucha de clases y en la demanda de igualdad y/o de inclusión dentro de la esfera política formulada por ciertos grupos sociales determinados por características particulares; como ejemplo tomemos la primera ola del feminismo, del siglo XIX a principios del xx, que perseguía objetivos concretos de participación e igualdad como el derecho al voto o a la propiedad (Offen, 1988, p. 123).

Sin embargo, tras las dos guerras mundiales y la reorganización política de poderes, la avanzada de la economía global y la hegemonía norteamericana, en 1960 surgió una nueva ola de movimientos sociales. Según Mouffe (1984), los llamados «nuevos movimientos sociales» emergieron en respuesta a los nuevos antagonismos producto del desarrollo de sociedades capitalistas, es decir, de la mercantilización de la vida social, y la presencia cada vez más extensa del Estado en la vida cotidiana. Las nuevas formas sociales que ha creado el modelo capitalista produjeron también nuevas experiencias de subordinación, lo que trajo como consecuencia la politización de espacios que previamente habían sido considerados privados o apolíticos (citada en Chesters y Welsh, 2011, p. 14).

Los nuevos movimientos sociales abarcan problemas sociales y políticos mucho más extensos y menos concretos que los asuntos económicos que se asocian a los primeros movimientos sociales. Entre estos están la lucha por los derechos civiles y políticos y contra la discriminación racial, el movimiento gay, las protestas contra la guerra, y la segunda ola del feminismo que ya no buscaba simplemente la inclusión de las mujeres dentro del esquema de poder sino algo más radicalmente abstracto y personal: la liberación sexual, el retorno del cuerpo a sus dueñas.

\section{Movimientos estudiantiles}

Por supuesto, dentro de los llamados nuevos movimientos sociales se incluye el movimiento estudiantil, que ocupó un lugar destacado dentro de la esfera social de la época: en concordancia con los movimientos de entonces, el estudiantil no se basaba en una lucha de clases, ni perseguía - necesariamente- objetivos concretos que implicaran un beneficio directo para los que participaban de él (como la reducción de tarifas estudiantiles, etc.) sino que se basaba en lo que Marcuse (1969, p. xviii-xix) llamó el Gran Rechazo: la protesta contra todos los tipos de poderes autoritarios y represivos.

Ahora, si bien la década de 1960 fue un periodo decisivo para el activismo estudiantil en todo el mundo, no debe olvidarse que la resistencia organizada de los estudiantes universitarios precede con mucho a la universidad moderna, y sus raíces se extienden 
hasta el siglo XIII cuando los primeros colectivos de estudiantes en la Universidad de Boloña hicieron protestas efectivas contra las políticas económicas de la ciudad (Boren, 2001, p. 4 y p. 10).

Pero son factores tales como la masificación de la educación universitaria en la época de la postguerra, el crecimiento económico, la incorporación del sistema educativo dentro del sistema económico como una etapa previa necesaria para acceder al siguiente paso en el ciclo laboral (Barker, 2008, p. 54), además del desfase entre acceso a la educación y acceso a un buen trabajo - algo que se hace cada vez más evidente - y la transformación de la universidad en un producto de consumo (o, dicho de otro modo, la transformación de las universidades en empresas privadas proveedoras de un servicio educativo) los que están estrechamente conectados con el surgimiento de este nuevo movimiento estudiantil en la década de 1960 (p.48).

No es exageración afirmar que el movimiento estudiantil en diferentes lugares del planeta fue no solo accesorio/aledaño a los procesos de contestación civil de la época, sino que en muchos casos fue su motor. Particularmente en 1968, los movimientos sociales y las explosiones sociales, que provocaron en universidades en todo el mundo, contribuyeron más que ningún otro grupo a producir un cambio en el clima social (Barker, 2008, p. 83); alteraron ideas y valores considerados evidentes en la sociedad capitalista. El movimiento estudiantil cuestionó desde formas de vida y suposiciones culturales, hasta decisiones políticas.

Es en este momento, en el pico de las revueltas estudiantiles (de 1968 a 1970), y cuando el sentimiento rebelde se extendía por todo Occidente (en el que incluimos a Japón), cuando Poniatowska y Takano escriben los relatos que analizaremos a continuación.

\section{La noche de Tlatelolco}

La noche de Tlatelolco de Elena Poniatowska es una recolección de testimonios varios de estudiantes, trabajadores, activistas, huelguistas, madres y artistas, además de consignas, carteles y coros; es un montaje polifónico que agrupa distintas perspectivas y voces sobre el episodio despiadado. Es un texto fragmentado, hecho trizas y reconstruido, que se niega a seguir una convención narrativa y que recrea, de esta manera, la consigna estudiantil de rechazar la autoridad (en este caso, narrativa).

En su libro, Poniatowska «se dedicó a oír las múltiples voces de los protagonistas -indiferentes, solidarias, quejumbrosas o airadas- y compuso este enorme testimonio colectivo, que, a la manera de un coro plural, da la relación de los hechos» (Poniatowska, 2001 , contraportada). La autora en su relato no busca establecer la verdad de los hechos de la matanza de Tlatelolco, sino recoger la experiencia de los múltiples actores y testigos de la tragedia. Al tiempo que evita acogerse a alguna versión oficial (que solo podría ser arbitraria) de lo ocurrido antes y después de la masacre, Poniatowska acepta las contradictorias versiones de los hechos y deja al lector libre para crear su propia lectura de la historia.

El texto se divide en dos partes: la primera, Ganar la calle, describe los eventos que precedieron a la matanza, durante la llamada Revolución del 68, entre los que deben destacarse dos momentos victoriosos, primero, la marcha hasta el Zócalo el 27 de agosto (una marcha multitudinaria que conquistó la plaza mayor de la ciudad de México, llegando incluso, con la autorización del párroco, a marcar su arribo a la plaza sonando las campanas de la catedral), y, segundo, la marcha del silencio del 3 de septiembre de 
1968, así como un momento aciago: la toma militar de la Ciudad Universitaria, con la consecuente brutalidad policial, desde el 18 de septiembre hasta el 1 de octubre, un día antes de la masacre.

La segunda parte, La noche de Tlatelolco (Poniatowska, 2001) que recoge las voces de la masacre misma, es aún más descarnada y cruel que la primera, y pone al lector a escuchar lo que preferiríamos acallar: la voz de la muerte, del abuso.

Hermanito, ¿qué tienes? Hermanito, contéstame... Hermanito, háblame... ¡Una camilla por favor! Hermanito, aquí estoy... ¡Una camilla!... ¡Soldado, una camilla para una persona herida!... Hermanito, ¿qué te pasa?... Hermano, contéstame... ¡Una camilla! [...] (p, 186).

¡Cállate y échate si no quieres dos! [...]Cállate, hijo de la chingada. [...] (p. 187).

¡Déjenme ir con él, soy su hermana! [...] Hermanito, ¿por qué no me contestas? [...] (p. 188).

Julio tenía 15 años [...] era la segunda vez que asistía a un mitin político. El me invitó a ir ese día. La primera vez fuimos los dos juntos a la gran manifestación silenciosa. Julio era mi único hermano (p. 189).

Aunque la crónica estremecedora y dolorosa muestra sin reserva la herida que esta matanza abrió en la sociedad mexicana, es claro que no es éste un relato lastimero que busque poner a los estudiantes en la posición de víctimas. La noche de Tlatelolco da voz a todos los participantes de los eventos del 2 de octubre, desde los estudiantes y trabajadores, los delegados y líderes del Movimiento Estudiantil Popular (MEP) y del Comité Nacional de Huelga (CNH) (es decir, los directos afectados por el ataque rastrero), hasta a los testigos no participantes, a los injustamente encarcelados, a los opositores del movimiento estudiantil, a las madres. El texto, además, incluye extractos de documentos oficiales, recortes de prensa y transcripciones de audios capturados en el medio del ataque.

La importancia de esta estructura narrativa hecha de retazos radica en el hecho de que en La noche de Tlatelolco la verdad histórica es un cristal hecho añicos cuyos fragmentos no consiguen, al ser juntados, reconstruir una imagen diáfana de lo ocurrido en octubre de 1968. Más que un relato cronológico sin fisuras evidentes, se trata de un texto en el que el quiebre, la contradicción y disonancia cargan la estructura de la narración. Como afirma Harris (2005, p. 488), la estrategia narrativa de Poniatowska de yuxtaponer versiones contradictorias sobre el mismo evento - por ejemplo, sobre quién hizo el primer disparo - sirve no solo para expresar los conflictos de interpretación sino para contradecir y socavar la dudosa versión oficial de los hechos.

Una de las voces presentes en la polifonía de este texto es la de la madre, que aparece repetidas veces y bajo diversas formas en el texto de Poniatowska; no se trata solo de la madre que llora al hijo muerto:

Yo siento que vivo ya una vida de segunda mano [...]

Y ahora, ¿qué voy a hacer yo de todo este tiempo que será mi vida? [...]

Señor, ¿dónde está mi hijo? ¿A dónde se los han llevado? (Poniatowska, 2001, p. 149)

También se trata de la madre intransigente y autoritativa que reprueba la rebeldía sin razón de su prole:

¿Por qué andas tan rabona? Además, no sabes sentarte [...]

Oye tú, greña brava, ¿qué no te di para la peluquería? [...]

¿Por qué no mejor sales en cueros? (pp. 23-24) 
Así como de la madre que se opone al movimiento juvenil:

¡Que no me vengan con cuentos! Si hay porquería en el gobierno también la hubo en el otro bando: el de los estudiantes y los adultos que los respaldaban (p. 68),

Y, por supuesto, de la madre que apoya al movimiento de estudiantes y se hace parte de él:

¿No hubiera sido mejor hablarles a los estudiantes? (p. 35)

Lo más vergonzoso que ha logrado Tlatelolco es amedrentar a los jóvenes (p. 93)

A mí me encanta la juventud de hoy, su moda, sus canciones, su libertad, su falta de hipocresía (p. 25)

Me han matado a mi hijo, pero ahora todos ustedes son mis hijos (p. 273).

La insistencia de Poniatowska en subrayar la condición pluridimensional de la mujer $-\mathrm{y}$ sobre todo de la madre - a través de este montaje ecléctico de voces, no solo logra dar una perspectiva de género a la narrativa histórica de este suceso (Harris, 2010, p. 114) sino que evita el lugar común de la representación de la madre como un personaje pasivo, desprovisto de contenido político, y la transforma en cambio en una figura compleja.

Por último, debemos hacer hincapié en un elemento que se repite en La noche de Tlatelolco: el diálogo o, mejor, la imposibilidad de éste. Las manifestaciones políticas que precedieron a la matanza de Tres Culturas, incluso la famosa Marcha del Silencio, compartían el objetivo común de reclamar un diálogo abierto con los estamentos de poder: «todas las escuelas estaban convencidas de que no había otro camino de solución que el diálogo público [...] Nosotros no podíamos transigir: el diálogo tenía que ser público» (Poniatowska, 2001, p. 75). Este clamor por un diálogo público —que, en últimas, reconociera a los manifestantes como interlocutores válidos, como mayores de edad-, se estrella contra un muro de metralla que replica el silencio patriarcal en el que han crecido: «Los únicos momentos en que me llevo bien con mis papás es cuando vamos al cine, porque entonces nadie habla» (p. 25); «En la noche, mis padres están demasiado cansados para hablar. Comemos. Nos dormimos. Con quienes hablo es con los ñeros en la Nocturna» (p. 26).

Tanto en la figura del gobierno como en la de los padres se repite el silencio, como única respuesta al clamor por el diálogo. Los testimonios en La noche de Tlatelolco alzan la reclama: «¿No hubiera sido mejor hablarles a los estudiantes desde su balcón?» (Poniatowska, 2001, p. 35); «si en alguna de las veces que fuimos al Zócalo el presidente sale al balcón y le hace frente a la multitud [...] se hubiera ganado a muchos compañeros» (p. 34).

Es posible afirmar que el diálogo que el gobierno se negó a ofrecer a los estudiantes se hace posible a través de la narrativa en montaje de Poniatowska: el encuentro intercalado de diferentes voces, que no esconde la contradicción inherente al intercambio, es la posibilidad que concede La noche de Tlatelolco y probablemente, también, una de las razones para su inmensa popularidad.

\section{El origen de mis veinte años}

Pasemos ahora al segundo texto: El origen de mis veinte años ${ }^{1}$, de Etsuko Takano. El título, de difícil traducción puesto que genten (原点) puede significar tanto raíz u origen - como he traducido aquí- como punto de partida, retrata la ironía de un origen o un 
punto de partida que coincide con la muerte: Takano se suicida a pocos meses de haber cumplido veinte años.

Si Poniatowska era una escritora reconocida para el momento en que se publicó $L a$ noche de Tlatelolco, Takano tenía solo veinte años al momento de escribirlo y había muerto dos años antes de su publicación. Este libro contiene las reflexiones escritas en su diario desde el 2 de enero de 1969 hasta el 22 de junio del mismo año, dos días antes de su suicidio.

Es necesario anotar que entre las décadas de 1960 y 1970, las casas editoriales japonesas atravesaban un boom de publicación de manuscritos póstumos (diarios, cuadernos, etc.) de jóvenes activistas del movimiento estudiantil. Entre los más conocidos están La tumba de la juventud (Seishun no bohyo『青春の墓標』) de Kohei Oku (1965) y La sonrisa que nadie conoce (Hitoshirezu hohoeman 『人しれず微笑まん』) de Michiko Kanba (1960). El clima político de la época y la simpatía que despertaba la figura de estos héroes caídos hizo que muchos de ellos se convirtieran en best-sellers. El de Takano no solo fue uno de los libros más leídos de 1971, llevado al cine en 1973, sino que su fama alcanzó para que se publicaran dos volúmenes más, uno en 1974 llamado Prefacio para El origen de mis veinte años, con sus diarios de 1966 a 1968, y otro en 1976, Notas para El origen de mis veinte años, con sus diarios de 1963 a 1966.

La obra de Takano fue, sin lugar a duda, tremendamente popular pero debe aclararse que no solo no fue la primera de este género, sino que probablemente tampoco haya sido la que tratara con más rigor los temas políticos de la época, o la que tenga mayor valor literario, y tampoco convirtió a Takano en la figura estudiantil más importante de esta generación. Si he dicho que Takano no es la más representativa de las mártires del movimiento estudiantil, es porque este lugar lo ocupa Michiko Kanba con su diario póstumo La sonrisa que nadie conoce (1960).

Kanba, nacida en el seno de una familia intelectual, estudiante de literatura de la Universidad de Tokio, fue asesinada el 15 de junio de 1960 por miembros de las fuerzas anti-motines, un escuadrón paramilitar llamado kidotai (機動隊). Su muerte no fue reconocida por el estamento oficial, y la única declaración pública al respecto de esta muerte la catalogó como muerte por aplastamiento, desmintiendo las voces de múltiples testigos oculares, presentes en la manifestación que tuvo lugar el 15 de junio de 1960 frente al edificio de la Dieta, en Tokio.

Si bien es menester guardar las proporciones con respecto al número de caídos, la protesta de junio de 1960 en Tokio puede ser equiparada, por la violencia desplegada por las fuerzas oficiales y por el número de participantes de las protestas (no solo estudiantes, aunque estos eran su motor principal) al 2 de octubre de 1968 en México.

Esta protesta es de gran importancia para la historia del Japón contemporáneo, porque marca el punto más elevado del antagonismo entre el pueblo movilizado y el gobierno. En 1960, un amplio grupo de ciudadanos, encabezado por el movimiento estudiantil llamado Zengakuen (全学連), llevó a cabo múltiples protestas contra la ratificación del tratado de seguridad entre Estados Unidos y Japón (conocido como Anpo 安保 en japonés), que básicamente perpetuaba el intervencionismo militar americano en suelo japonés, probablemente la última coda de la derrota japonesa en la Segunda Guerra Mundial (Andrews, 2010, p. 39).

Tras su muerte, Kanba se convirtió en una especie de Juana de Arco de la lucha revolucionaria estudiantil en Japón, compartiendo no solo el rasgo de la muerte heroica, sino el halo de santidad virginal (no hay ningún rasgo erótico en el diario de Kanba, a 
diferencia del de Takano), y un cierto tufillo de alcurnia, pues también a diferencia de Takano, Kanba sí era parte de la élite intelectual japonesa, no solo por pertenecer a la Universidad de Tokio, sino por ser una de las cabecillas del movimiento estudiantil.

Y aunque Takano admirase a Kanba, a diferencia de ella, en su diario Takano revela un talante dramático y autocrítico, evidente en la línea que da título a su libro: «En mi soledad, en mi inmadurez, allí está el origen de mis veinte años» (Takano, 2017, p. 14). El estilo de sus diarios pone en evidencia esta diferencia: allí donde Kanba era disciplinada y crítica, Takano es frágil y sentimental (Ishikawa, 2016, p. 22).

Takano se pregunta incesantemente sobre sí misma, sobre quién es y sobre cuánto la determinan los papeles que le asignan los demás: «Cuando ingresé a esa comunidad que es la escuela, se me asignaron los roles de "la chica buena", "la chica dócil", "la chica amable", "la chica alegre". Puede que algunos de estos roles fueran adecuados para mí. Pero, puesto que era una persona timidísima, una chica asustada frente a un mundo y a una gente extraña, simplemente desempeñaba el papel de "niña linda que tiene buenas calificaciones" que se me asignó» (Takano, 2017, p. 16). La institución educativa, para Takano, le ha impuesto un rol que, si bien no está en desacuerdo con ella, tampoco es el de su elección.

En la protesta estudiantil, tanto como en la escritura de su diario, Takano parece encontrar un medio para satisfacer su deseo de separarse de ese $y o$ asignado y trocarlo por un yo construido (libre y artificialmente) por sí misma: «yo quisiera convertirme en una persona que crea, no en este yo al que me han acostumbrado a ser» (p. 15).

La acción, que como hemos mencionado en el primer apartado de este artículo es concomitante con los movimientos sociales, toma en el caso de Takano un matiz especial: no es ya de la acción radical de lo que se trata, sino del actuar en tanto que performance. La vida, dice Takano repetidamente, es actuación (p. 17, p. 67, etc.). En este punto, la joven oscila entre un yo verdadero y una ficción.

Según Sekigawa (citado en Ishikawa, 2016, p. 22), para Takano la escritura de su diario no se convirtió en un escape, sino que se transformó en un espejo de lo que Takano consideraba su fealdad, o su necesidad de afearse. La literatura para Takano era más bien un lugar donde conservar secretamente la culpa, la vergüenza y las reflexiones. Es decir, la literatura se convirtió para Takano en una forma de autoflagelación. Junto a otros héroes caídos del movimiento estudiantil como Kanba y Oku, Takano y los jóvenes relatores de su época encarnaban el dilema de, por un lado, conocer el sinsentido de la escritura, y por el otro, saber que solo a través de la escritura pueden conocer el rastro de su existencia (Ishikawa, 2016, p. 25).

\section{De la polifonía al monólogo: una comparación}

Los textos de Poniatowska y Takano no solo comparten la fecha de publicación y el contexto histórico de los movimientos estudiantiles, sino que ambos, de maneras ciertamente disímiles, consiguen construir narrativas no oficiales, paralelas y resistentes a la narrativa histórica de los sucesos del fin de los años 60 . No significa esto que carezcan de validez histórica, pero a comprobar la veracidad de los testimonios consignados en sus páginas se dedicarán quienes en ellas reclamen la precisión de la crónica histórica. Nosotros intentaremos ver qué lazos se tienden, de un extremo del mundo al otro, entre estas dos narrativas. 


\subsection{La voz que se construye}

En su libro, Poniatowka (2011) logra con maestría retratar el coro polifónico que narra tanto la vitalidad de las protestas, como el terror y la desolación de la muerte. En un entramado de estilos y ritmos, en el texto de Poniatowska las palabras no son solo relato. A veces son canto iterativo:

MÉ-XI-CO-LI-BER-TAD- MÉ-XI-CO-LI-BER-TAD- MÉ-XI-CO-LI-BER-TAD (p. 15)

ÚNETE PUEBLO ÚNETE PUEBLO ÚNETE PUEBLO ÚNETE PUEBLO (p. 15)

DIA-LO-GO-DIA-LO-GO-DIA-LO-GO- DIA-LO-GO-DIA-LO-GO (p. 20)

CHE CHE CHE GUEVARA CHE CHE CHE GUEVARA CHE CHE CHE (p. 31)

HO-HO-HO-CHI-MINH, DÍAZ ORDAZ, CHIN, CHIN, CHIN, HO-HO-HO (p. 97)

A veces, poesía:

¿Y a esa luz, breve y lívida, quién? ¿Quién es el que mata?

¿Quiénes los que agonizan, los que mueren?

¿Los que huyen sin zapatos?

¿Los que van a caer al pozo de una cárcel?

¿Los que se pudren en el hospital?

¿Los que se quedan mudos, para siempre, de espanto?

¿Quién? ¿Quiénes? Nadie. Al día siguiente. Nadie. (p. 163)

$\mathrm{Y}$ a veces son una red que intenta contener, infructuosamente, un grito:

ese grito distorsionado que todo lo rompe, el ay de la herida definitiva, la que no podrá cicatrizar jamás, la de la muerte del hijo (p. 164).

Poniatowska dice con precisión:

aquí está el eco del grito de los que murieron y el grito de los que quedaron [...] es el grito mudo que se atoró en miles de gargantas [...] por el espanto del 2 de octubre de 1968, en la noche de Tlatelolco (p. 164).

Con la suma de estos relatos el grito es liberado, como proferido por un sujeto creado gracias al montaje de trozos aparentemente inconexos. El cuerpo de los movimientos sociales, esa masa aglutinada, creada a punta de identificación, en la que el individuo desaparece para dar paso al ideal, cobra subjetividad en el relato y permite a todas sus voces hablar simultáneamente.

El diario de Takano comparte con el texto de Poniatowska la multiplicidad de recursos estilísticos, entre los que sería imposible no mencionar la poesía. El último de los relatos del diario, que quedaría como carta de despedida antes de su suicidio, rompe el estilo descriptivo de otras entradas, y anuncia con cruel inocencia el viaje a emprender:

Vamos de viaje

En la maleta, una tienda de campaña y un saco de dormir

En el bolsillo solo una caja de tabaco y una flauta

Vamos de viaje (Takano, 2017, p. 226).

Sin embargo, allí donde Poniatowska abre un canal para que todas las voces del movimiento sean oídas, Takano hace del movimiento estudiantil el telón de fondo para que una única voz se levante y abra la pregunta que se convertirá en el eje de la narración: la pregunta por el yo. Takano se cuestiona incesantemente por la condición del individuo 
adentro del movimiento estudiantil.

Reaparece así en El origen de mis veinte años el individuo que ha sido eliminado bajo el manto heroico de la narrativa común del movimiento estudiantil. Esta individualidad, descarnada y burda, está hecha de inmadurez, de soledad, de debilidad, de contradicciones, en suma, de una angustia que contrasta con la grandeza heroica del movimiento y de los intereses intelectuales. «Mi hermana, en la lucha en la Universidad Nihon. Mi hermano, en medio de sus exámenes de grado, golpeándose contra el muro del capital monopolista... Pero el sentimiento que me captura hoy a mí es un sentimiento de angustia» (Takano, 2017, p. 58).

\subsection{La brecha expuesta}

Si bien las voces narrativas en ambos textos difieren drásticamente, tanto La noche de Tlatelolco como El origen de mis veinte años comparten un elemento gracias al cual podemos reconocer su valor crítico dentro del movimiento estudiantil. Ambos textos, cada uno desde su perspectiva, exponen el conflicto que reside en el corazón de los movimientos de la época. Veamos qué formas adquiere este conflicto, esta brecha, en las dos narraciones.

Poniatowska por su parte revela la distancia entre el lenguaje y la acción, encarnada en dos de los actores del movimiento social: un conflicto de lenguajes que reclaman algunos de los partícipes del movimiento: los trabajadores y los estudiantes. Mientras la lucha de los estudiantes parece encerrada en una trampa de palabras:

Yo soy de la UNAM y allá se maneja un lenguaje académico, de grupo. Aquí la educación es clasista. [...L] os muchachos [...] hablaban de lucha de clases y nadie los entendía. No había comunicación (Poniatowska, 2001, pp. 28-29)

Los trabajadores y miembros de movimientos obreros mostraban su inconformidad con la falta de acción:

Los teóricos no salían a brigadas; se quedaban encerrados cotorree y cotorree nomás perdiendo el tiempo» (p. 35).

Aunque la oposición entre estos dos sectores del mismo movimiento y el rechazo a la clase obrera se hacen patentes en las siguientes citas:

Los obreros no saben nada $[\ldots]$

Lo que pasa es que los obreros son bien reaccionarios [...] (p. 42)

No se puede romper el control gubernamental en fábricas y sindicatos (p. 43)

También se debe, en toda justicia, recordar que Poniatowska no olvida recoger la opinión contraria y enfrentarlas para así hacer imposible una simple división entre dos bandos:

[...]muchos trabajadores empezaron a simpatizar con la causa estudiantil, porque vieron que los estudiantes también se preocupaban por ellos y los incluían en su lucha [...]

No es cierto que los estudiantes estuvieran solos, y que los obreros no les echaran ni un lazo (p. 47).

Dando voz a este conflicto entre lenguaje y acción, Poniatowska hace evidente la lucha de clases que yace no solo en el movimiento social de la década de 1960 sino en el corazón de la universidad misma, una institución creada originalmente para élites 
ilustradas (Boren, 2001, p. 4), y cuya permanencia en la era contemporánea es posible gracias a la masificación de la educación y la inclusión de los descendientes de la clase obrera en la institución educativa.

Takano también toca este conflicto, revelando el inconformismo de los estudiantes que ven la cara corporativa de la universidad y confirman que no es ya el saber sino el capital la columna central la institución:

La organización universitaria no se compone por la relación directa entre maestros y estudiantes, pues además de los departamentos y las facultades hay sección de finanzas y sección de asuntos generales, y juntas directivas... en realidad se siente mucho más como una corporación (Takano, 2017, p. 20).

$\mathrm{Si}$, como hemos mencionado anteriormente, los movimientos sociales emergieron en respuesta a la mercantilización de la vida social, el movimiento estudiantil debe haber nacido como respuesta a la capitalización de la universidad. Pero para Takano, quien pone en evidencia en su diario el conflicto del individuo dentro de la masa de protesta, la lucha no es solo la búsqueda del derrocamiento de la institución sino la constitución de una subjetividad nueva y radical:

La existencia de la universidad, la existencia de la academia, se sustenta en la lógica del capital. Yo busco convertirme, negando esa universidad, esa academia, esa educación, ese "hacerse estudiante porque sí", en una verdadera estudiante, de forma permanente, como en una lucha sangrienta (Takano, 2017, p. 184).

Takano, al afirmar que «estas notas constituyen la única yo» (Takano, 2017, p. 54) emplea la escritura como una herramienta para construir una relación entre el yo que escribe y el yo sobre el que se escribe. En oposición a la acción de la protesta, Takano opta por la palabra y convierte la escritura en un medio para cubrir y a la vez revelar -en una especie de exhibición fetichista - su ignorancia.

«No hay que tener medio de poner la inmadurez propia en evidencia ante los demás. El hecho de que no se conozca ni la M del marxismo no significa que no se pueda luchar contra la clase dominante actual [...] Mi lucha es por el ser humano, para devolver al ser humano su lugar. Es una lucha por la libertad. [...] Para que el yo pueda ser el yo mismo, aún en su inmadurez, debe exponerse enteramente (Takano, 2017, p. 197).

Estos dos relatos muestran con agudeza cómo, a pesar de que el movimiento estudiantil existe gracias a la institución universitaria que lo alberga, es a la vez su más acérrimo crítico. En ellos vemos aparecer la dicotomía entre la universidad como lugar de la palabra y los trabajadores como verdaderos dueños de la acción, y encontramos la dicotomía entre la universidad como institución capitalista y el individuo ansioso de liberación.

\section{Conclusión}

Poniatowska, a través del coro polifónico, discordante y contradictorio, pero radicalmente igualitario, crea el diálogo que le fue negado a los estudiantes de Tlatelolco cuando fueron atacados. Takano, a su vez, construye la pregunta por la propia identidad con los fragmentos que quedan de la resistencia estudiantil, se sumerge en un monólogo interno aislado del reclamo social y se responde con angustia que, aun siendo parte del cuerpo estudiantil, el yo es siempre inmaduro, incompleto, solitario, irredimible, «Lo que apoya a este yo solitario soy solo yo» (Takano, 2017, p, 112). 
Hemos resumido los encuentros y desencuentros que ofrecen estas dos narrativas de la siguiente manera (Tabla 1). Allí donde Poniatowska se borra como autora para dejar pasar todas las voces de Tlatelolco a través suyo, dando cuerpo a un mar de voces que habían sido acalladas, Takano intenta contener todo el barullo de los estudiantes en revuelta y escribe, erotiza, teatraliza (actúa, en ese sentido), nombra con su acto a la protesta estudiantil y se hace el sujeto que vive la protesta para, finalmente, abandonarse sin ningún trazo de heroísmo al viaje eterno.

Tabla 1. Comparación de las obras mencionadas.

\begin{tabular}{|l|l|l|l|}
\hline \multicolumn{1}{|c|}{ Obra } & \multicolumn{1}{|c|}{$\begin{array}{c}\text { La voz que se } \\
\text { construye }\end{array}$} & \multicolumn{1}{c|}{ La brecha expuesta } & \multicolumn{1}{c|}{ El producto } \\
\hline $\begin{array}{l}\text { La noche de } \\
\text { Tlatelolco }\end{array}$ & $\begin{array}{l}\text { Movimiento estudiantil: } \\
\text { multiplicidad de voces } \\
\text { antes acalladas (canto, } \\
\text { grito, poesía) }\end{array}$ & $\begin{array}{l}\text { Lenguaje (estudiantes) vs. } \\
\text { acción (trabajadores) }\end{array}$ & $\begin{array}{l}\text { Diálogo negado por el } \\
\text { gobierno, abierto gracias a } \\
\text { la narración }\end{array}$ \\
\hline $\begin{array}{l}\text { El origen de mis } \\
\text { veinte años }\end{array}$ & $\begin{array}{l}\text { Movimiento estudiantil: } \\
\text { fondo para construir } \\
\text { el Yo, (individualidad, } \\
\text { angustia, contradicción) }\end{array}$ & $\begin{array}{l}\text { Universidad como corpo- } \\
\text { ración. Acción como } \\
\text { actuación. }\end{array}$ & $\begin{array}{l}\text { Monólogo, cerrado, no } \\
\text { busca interlocutores. } \\
\text { Termina en el acto radical } \\
\text { del suicidio. }\end{array}$ \\
\hline
\end{tabular}

\section{Referencias bibliográficas}

Andrews, W. (2016). Dissenting Japan. Londres: Hurst \& Company.

Barker, C. (2008). Some Reflections on Student Movements of the 1960s and Early 1970s. Revista Crítica de Ciencias Sociais, 81, pp. 43-91. Recuperado de http://rccs.revues.org/646

Boren, M. (2001). Student Resistance: A History of the Unruly Subject. New York: Routledge.

Chesters, G. y Welsh, I. (2011). Social Movements: The Key Concepts. New York: Routledge.

Harris, C. (2005). Remembering 1968 in Mexico: Elena Poniatowska's La noche de Tlatelolco as Documentary Narrative. Bulletin of Latin American Research, 24 (4), pp. 481-495.

Harris, C. (2010). Luis González de Alba's Los dias y las noches (1971) and Elena Poniatowska's La noche de Tlatelolco (1971): Foundational representations of Mexico '68. Bulletin of Latin American Research, 29 (1), pp. 107-127.

Ishikawa, K. (2016). Nikki no naka no hiroizumu: Kanda Michiko, Oku Kohei, Takano Etsuko [El heroísmo dentro de los diarios: Kanda Michiko, Oku Kohei, Takano Etsuko]. Kindai Bungaku Godo Kenkyukai Ronshu, 12, pp. 2-26.

Kanba, M. (1960). Hitoshirezu hohoeman: Kanba Michiko Ikoushuu [La sonrisa que nadie conoce: escritos póstumos de Kanba Michiko]. Tokio: San-ichi Shobo.

Marcuse, H. (1969). An Essay on Liberation. Boston: Beacon Press.

Marx, G. y McAdam, D. (1994). Collective Behaviour and Social Movements. Englewood Cliffs, NJ: Prentice Hall.

Melucci, A. y Massolo, A. (1991). La acción colectiva como construcción social. Estudios Sociológicos, 9 (26), pp. 357-364.

Mouffe, C. (1984). Towards a Theoretical Interpretation of New Social Movements, Rethinking Marx. New York: International General/MMRC.

Offen, K. (1988). Defining Feminism: A Comparative Historical Approach. Signs, 14 (1), pp. 119-157.

Poniatowska, E. (2001). La noche de Tlatelolco (2a edición, corregida). México D.F.: Ediciones Era.

Takano, E. (2017). Nijusai no genten [El origen de mis veinte años]. Tokio: Shinchosha.

Thompson, N. (2002). Social movements, Social Justice and Social Work. British Journal of Social Work, 32, pp. 711-722. 


\title{
Notas
}

${ }^{1}$ Todas las traducciones son de la autora.

\section{Perfil de la autora}

Egresada de la Facultad de Ciencias Humanas de la Universidad Nacional de Colombia y Doctora en Ciencias Humanas y Ambientales de la Universidad de Kioto. Especialista en literatura japonesa contemporánea, su investigación se centra en hacer una lectura desde la teoría psicoanalítica de la obra de autores japoneses de la postguerra. Autora de varios artículos sobre la obra de Mishima Yukio, también ha trabajado en traducciones de otros autores contemporáneos, algunas de las cuales hacen parte de la antología El Japón de los perros (2020, Satori). Profesora de literatura y cultura japonesa en la Universidad Doshisha y la Universidad Femenina de Doshisha, y de lengua española y cultura de Latinoamérica en la Universidad Ritsumeikan y la Universidad de Kioto.

\section{English Title}

Literature written by women and the student movement of the $1960 \mathrm{~s}$ : The narratives of Elena Poniatowska and Etsuko Takano

\begin{abstract}
The objective of this article is to compare two texts written by women in the context of the student movements of the 1960s: Mexico's Elena Poniatowska's Massacre in Mexico (La noche de Tlatelolco) and Japan's Etsuko Takano's The Origin of Being Twenty (Nijusai no genten), both texts published in 1971. Poniatowska's document depicts the multiplicity of voices that formed the student movement in 1960s Mexico, and through a polyphonic montage, she offers the dialog that the students were deprived of when they were violently attacked. Takano's diary, on the other hand, written in an intimate, confessional and anxiety-filled tone, portrays the movement as the background against which the question for one's own identity appears. Both authors, although through very different literary forms, share the fact of narrating the turbulent years of protests from perspectives that oppose and contradict historical or official narratives: for Poniatowska as a dialog, and for Takano as an inner monologue.
\end{abstract}

\section{Keywords}

Elena Poniatowska, Etsuko Takano, student movements, 1960s

\section{日本語タイトル}

1960年代の女性文学と学生運動:エレナ・ポニアトウスカと高野悦子による物語

\section{要旨}

本稿では、1960年代の学生運動の文脈で女性が執筆した2つの語りを比較した。ひとつは メキシコのエレナ・ポニアトウスカ著『トラテロルコの夜』であり、もうひとつは高野悦子著『二十歳 の原点』である。両作品とも1971年に出版されている。ポニアトウスカのテクストは、60年代の メキシコ学生運動における多くの声を盛り込み、ポリフォニー的な語りを通じて、拒絶された対話に 代わる選択肢を学生たちに対し提供している。他方、高野の日記は親密な口調で告白と不安 を綴り、アイデンティティの自問の背景として学生運動を語っている。2人の作家はそれぞれ 文学的形式が異なるが、ポニアトウスカはオープンな対話、高野は内なる独白といら形式を 用いて、学生デモに摇れたこの時代を公式の歴史や現実に相対する形で表現した点に共通点 を見出すことができる。

キーワード

エレナ・ポニアトフスカ、高野悦子、学生運動、1960年代 